\title{
Adsorption Behavior of some N-alkyl Pyridinium Salts from Aqueous Solution on Amberlite-IR $120 \mathrm{H}^{+}$resin
}

\author{
NAJAH AYAD ALSHAMMARI ${ }^{1,2 *}$, EHTERAM A. NOOR ${ }^{1}$ and JAMILAH MOHAMMAD ALAHMARI ${ }^{1}$ \\ 'Department of Chemistry, Faculty of Sciences, King Abdulaziz University, Jeddah, Saudi Arabia. \\ 2Department of Chemistry, Faculty of Sciences and Art, Northern Border University (NBU), \\ Rafha, Saudi Arabia. \\ ${ }^{\star}$ Corresponding author E-mail: najah.a.j@ hotmail.com \\ http://dx.doi.org/10.13005/ojc/340312
}

(Received: April 03, 2018; Accepted: May 20, 2018)

\begin{abstract}
The effect of Amberlite-IR $120 \mathrm{H}^{+}$resin to remove some organic compounds ( $\mathrm{N}$-alkyl pyridinium salts) from aqueous solutions at certain conditions was investigated. The effect of resin dosage, contact time, adsorbate concentration, ionic strength and solution temperature on the adsorption efficiency was examined. The experimental data collected generally proved that the adsorption efficiency decreased as the alkyl chain increased. The thermodynamic equilibrium parameters of the adsorption processes were evaluated and showed that the adsorption process is spontaneous, disordered and exothermic. Langmuir, Freundlich, Temkin and Dubinin-Radushkevich (D.R) isotherm models were applied based on the batch method. Freundlich, Temkin and D. R gave bilinear segments model based on the adsorbate initial concentrations except that for compound III where it gave straight of one segment for Temkin adsorption isotherm. Overall, Amberlite-IR $120 \mathrm{H}^{+}$ resin is effective in removing some $\mathrm{N}$-alkyl pyridinium salts from an aqueous solution.
\end{abstract}

Keywords: Adsorption, Ion exchange, Isotherms, Thermodynamics, Resin, Removal, Pyridinium salts.

\section{INTRODUCTION}

Adsorption can be employed in a variety of applications particularly in the area of environment. For example, it is used to purify water from solvents or vice versa. Organic resins are the most useful type of adsorbents that used to remove heavy metals, dyes, fluoride, nitrate, ammonia and contaminants due to their high adsorption capacities and low cost. They are classified based on functional groups and whether they include cationic, anionic or amphoteric. Further classification is based on the strength of an acid or base ${ }^{1,2}$. Specially, Amberlite IR-120. $\mathrm{H}^{+}$is an excellent resin that can be used for a variety of water demineralization applications ${ }^{3}$.

Ion exchange and adsorption have similar diffusion processes. In both of them a substance is captured by solid particles. However, there are some different characteristics between them. For 
instance, lon exchange processes require releasing an equivalent amount of removed ions into the solution while adsorption processes do not demand any replacement of the removed ions ${ }^{4}$.

The adsorption isotherm relieves essential information about the adsorbent surface characteristics, and it represents the distribution of adsorbate between a liquid phase and a solid phase at equilibrium state. Langmuir adsorption isotherm assumes that the surface is homogeneous and consists of many active sites in which each one can adsorb only one molecule of the adsorbate forming monolayer adsorption. The Langmuir equation has the linear form of ${ }^{5}$.

$$
\mathrm{Ce} / \mathrm{qe}=\left(1 / \mathrm{q}_{\mathrm{m}} \mathrm{K}_{\mathrm{L}}\right)+\left(\mathrm{Ce} / \mathrm{q}_{\mathrm{m}}\right)
$$

Where " $\mathrm{q}_{\mathrm{m}}$ " and " $\mathrm{K}_{\mathrm{L}}$ " are the Langmuir constants related to adsorption capacity and energy of adsorption. Freundlich model is used to represent the adsorption characteristics for heterogeneous surfaces. Freundlich states that the adsorbate molecules interact with each other in multilayer adsorption. The Freundlich equation has the linear form ${ }^{6}$.

$$
\log q_{e}=\log K_{F}+1 / n \log C_{e}
$$

The sorption capacity $\mathrm{K}_{\mathrm{F}}$, which is the indication of the quantity of adsorbate onto adsorbent for a unit equilibrium concentration. Temkin model assumes that the heat of all molecules of a layer diminishes at a straight line with the coverage as a consequence of the interaction of adsorbent-adsorbate ${ }^{7}$.

$\mathrm{q}_{\mathrm{e}}=\mathrm{B} \ln \mathrm{K}_{\mathrm{T}}+\mathrm{B} \ln \mathrm{C}_{\mathrm{e}}$

$\mathrm{K}_{\mathrm{T}}$ is the equilibrium constant while $\mathrm{B}$ is related to the adsorption heat. D.R model estimates the mean free energy of the adsorption and determines whether the adsorption has the chemical or physical characteristic. The D.R equation has the form ${ }^{8}$.

$\ln \mathrm{q}_{\mathrm{e}}=\ln \mathrm{K}_{\mathrm{s}}-\mathrm{b} \varepsilon^{2}$

$\mathrm{K}_{\mathrm{s}}$ is the maximum adsorption capacity, $\mathrm{b}$ is a constant related to mean adsorption energy, and $\varepsilon$ is the Polanyi adsorption potential, which is equal to.
$\varepsilon=R T \ln \left[1+1 / C_{e}\right]$

The energy of adsorption is the free energy of the transfer of one mole of a solute from infinity (in solution) to the surface of the adsorbent. The mean value of adsorption energy $E$ can be computed using the following relationship.

$$
\mathrm{E}=\frac{1}{\sqrt{2 \mathrm{~b}}}
$$

$E$, mean free energy, is used to determine the type of adsorption process. For example, $\mathrm{E}<$ $8 \mathrm{~kJ} / \mathrm{mol}$ is for physisorption, $8<\mathrm{E}<16 \mathrm{~kJ} / \mathrm{mol}$ is for ion-exchange and $20<E<40 \mathrm{~kJ} / \mathrm{mol}$ is for chemisorption $^{8,9}$.

$\mathrm{N}$-methyl pridynium salts with different substituents had been successfully removed from aqueous solutions using dowex $50 \mathrm{WX} 4-5 / \mathrm{H}^{+10}$ where Freundlich and Dubinin-Radushkevich adsorption isotherm models fit well their adsorption data. The present work aimed to investigate the efficiency of Amberlite-IR $120 \mathrm{H}^{+}$resin for the removal of pridynium salts, having the same substituent but differ in the $\mathrm{N}$-alkyl chain, from aqueous solution under different conditions.

\section{EXPERIMENTAL}

\section{Chemicals}

$\mathrm{N}$-alkyl Pyridinium salts have been prepared and proven elsewhere ${ }^{11}$. Their chemical structure formula and molecular weight are given in Table 1. These compounds are classified as 1:1 electrolytes where the organic part has the electron-donor-acceptor properties ${ }^{12}$. Amberlite IR-120 resin (Functional group: $-\mathrm{SO}_{3} \mathrm{H}$; Matrix: Styrene divinylbenzene), supplied by the Dow chemical company, was used. The physical form (beads) is represented in Fig. 1. Moreover, analytical grade reagents of hydrochloric acid $98 \%(\mathrm{BDH})$, Silver nitrate, $\mathrm{AgNO}_{3}(\mathrm{BDH})$ and sodium chloride, (Sigma-Aldrich) were used.

\section{METHODS}

\section{Activation of Amberlite-IR $120 \mathrm{H}^{+}$resin}

The resin was initially activated with $\mathrm{HCl}$ (1 M) for $24 \mathrm{~h}$, then it was washed with deionized water several times until all chloride ions were removed. To ensure that the solution is chloride ions 
free, $\mathrm{AgNO}_{3}$ solution (0.1 M) test was used. After that, the resin was dried at $50{ }^{\circ} \mathrm{C}$ in an electric oven and stored at room temperature until use.

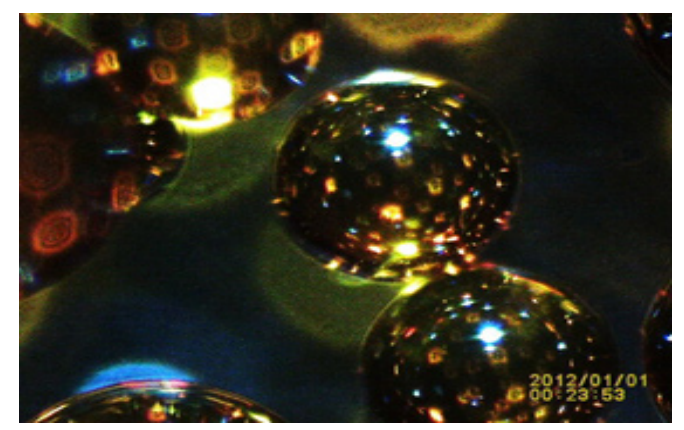

Fig. 1. Physical form of Amberlite IR-120.

The determination of the studied organic cations concentrations at equilibrium $\left(\mathrm{C}_{\mathrm{e}}\right)$

The absorbance of various dilutions (stock solutions, $5 \times 10^{-4} \mathrm{M}$ ) of the studied organic compounds were determined by spectrophotometric technique and was found to fit well Beer's law equation (non-zero intercept) ${ }^{13}$.

$\operatorname{Abs}\left(\lambda_{\max }\right)=b+a C$

Where $\operatorname{Abs}\left(\lambda_{\max }\right)$ measures the absorbance (no units), $a$ is a slop, $b$ is the intercept, and $c$ is the concentration $(\mathrm{M})^{14}$. $\lambda$ max was ranged from 306 to $390 \mathrm{~nm}$. In order to identify Ce, Eq (7) can be rearranged as follows.

$\mathrm{Ce}=\left(\mathrm{Abs}_{(\lambda \max )}-\mathrm{b}\right) / \mathrm{a}$

\section{Adsorption of the studied organic compounds on Amberlite IR $120 \mathrm{H}^{+}$resin}

Batch method was conducted to study the effect of resin dosage as follows: a certain amount of each studied organic compound was dissolved in $100 \mathrm{~mL}$ measuring flask to obtain a final concentration of $1 \times 10^{-3} \mathrm{M}$. Then, every time a different amount of the resin $(0.05,0.1,0.15,0.25$, 0.5 or $0.75 \mathrm{~g}$ ) was mixed with a solution of the studied compounds. After that, the solutions were stirred at a constant speed rate for $60 \mathrm{~min}$. at $30^{\circ} \mathrm{C}$. Finally, the solutions were separated from the resin after equilibrium and analyzed by UV spectrophotometric technique. The steps were repeated using a certain amount of the resine $(0.25 \mathrm{~g})$ for studying the effect of contact time, initial concentrations, ionic strength and solution temperature by varying respectively the contact time (5 to $80 \mathrm{~min}$.), initial concentrations of the studied compounds, $\left(2.5 \times 10^{-4}\right.$ to $\left.1.5 \times 10^{-3} \mathrm{M}\right)$, $\mathrm{NaCl}$ concentration $(0.05$ to $1.0 \mathrm{M})$ and solution temperature $\left(30-70{ }^{\circ} \mathrm{C}\right)$. All experiments were conducted at solution $\mathrm{pH}$.

The amount of the cations adsorbed per unit mass, $q_{e}\left(m^{\prime} l . g^{-1}\right)$ can be calculated as following.

$\mathrm{q}_{e}=\left(\mathrm{C}_{\mathrm{i}}-\mathrm{C}_{\mathrm{e}}\right) \times \mathrm{V} / \mathrm{m}$

Where $\mathrm{C}_{i}$ is the initial concentration, (mol.L-1 or M), $\mathrm{m}$ is the mass of the adsorbent $(\mathrm{g})$ and $\mathrm{V}$ is the volume of the solution $(\mathrm{L})$. The distribution coefficient $\left(K_{d}, L . g^{-1}\right)$ estimates the ability of the ion exchanger to remove certain ionic species from liquid medium. It can be measured by the following formula.

$K_{d}=\frac{C_{i}-C_{e}}{C e} \times \frac{V}{m}$

The adsorption percentage can be determined (Ads\%) according to the equation below.

Ads $\%=\frac{\left(C_{i}-C_{e}\right)}{C_{i}} \times 100$

\section{RESULTS AND DISCUSSION}

\section{Effect of resin dosage}

The removal efficiency of the studied compounds $\left(1 \times 10^{-3} \mathrm{M}\right)$ was investigated by varying the resin amount from 0.05 to $0.75 \mathrm{~g}$ at $30{ }^{\circ} \mathrm{C}$ and $60 \mathrm{~min}$. contact time (Fig. 2-a). It is clear that the $q_{e}$ decreased with increasing the resin dose. The interpretation, in this case, is that increasing the resin amount caused agglomeration of the resin particles leading to a reduction in inter-particle distances. So that, the intersecting of the adsorption sites as a result of the overcapacity of the resin particles led to decrease $q_{e}$. They also might be performed a screen on the outer layer of the particles covering the active sites from the adsorbate ${ }^{15}$. As it is shown from Fig. 2-b, $K_{d}$ increased dramatically as the adsorbent increased, to reach the highest value at $0.25 \mathrm{~g}$ of the resin, due to increasing the number of active adsorption sites and generating a greater 
surface area for a fixed adsorbate concentration with increasing the resin amount ${ }^{16}$. Then, $\mathrm{K}_{\mathrm{d}}$ declined with increase the adsorbent. The possible reason is that while the adsorbent concentration increased, some active sites still unsaturated during the adsorption process. As a result, more of free sites were formed ${ }^{17}$. By all means, increasing active sites with increasing adsorbent more than the concentration of the adsorbate itself. Therefore, a further increase of the adsorbent will discharge to decrease the adsorption. It might also be contributed to overlapping the active sites leading to a decrease of the surface area and accumulation of the exchanger particles ${ }^{18}$. Consequently, the selected amount of the resin for the remaining experiments was $0.25 \mathrm{~g}$.

\section{Effect of the contact time between adsorbent and adsorbate}

Figure 3 represents the effect of contact time (5-80 $\mathrm{min}$.) between the adsorbent and the adsorbate for the adsorption of organic compounds $\left(1 \times 10^{-3}\right)$ from aqueous solution on Amberlite

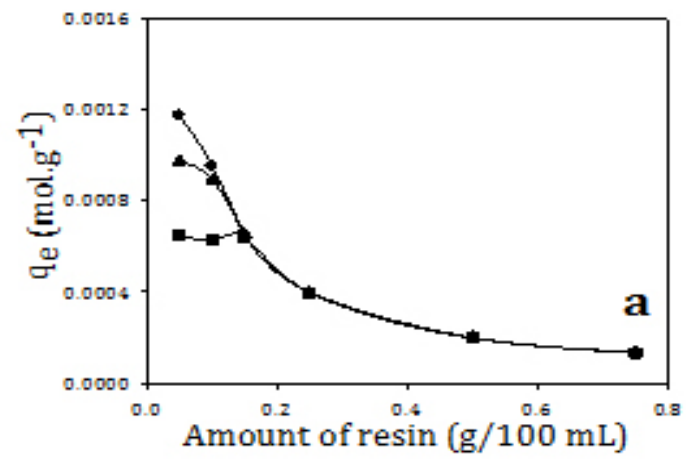

IR-120 $\mathrm{H}^{+}$resin $(0.25 \mathrm{~g})$ at $30{ }^{\circ} \mathrm{C}$. It is evident that the adsorption efficiency increased dramatically with increase the contact time until $60 \mathrm{~min}$. because all the active sites of the resin surface were vacant at initial and the adsorbent concentration gradient was significantly high. Hence, the functional groups of the resin surface need more time to bind entirely with the vacant active sites, since each active site of the resin surface adsorbs only one molecule of the adsorbate, and to achieve a sufficient equilibrium between the amount of the organic cations adsorbed by the resin and the amount of the cations remaining in the solution ${ }^{19}$. At 60 min., contact time, it was achieved an ideal time of the maximum organic cations removal and reached the equilibrium completely. As a result, the contact time used in our adsorption studies was 60 min., However, after 60 min., the adsorption efficiency became almost constant. The reason is that with further increase of the contact time, most of the active sites of the resin were occupied with the cations that cover the adsorbent surface. So that, the adsorption did not indicate a significant change

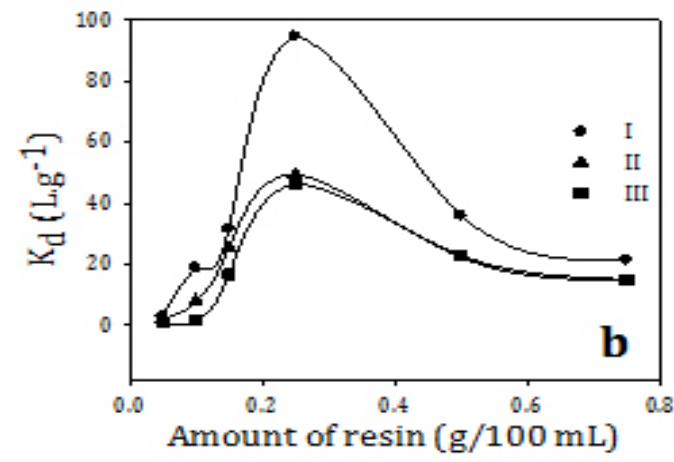

Fig. 2. Effect of amount of Amberlite-IR $120 \mathrm{H}^{+}$resin $(0.05-0.75 \mathrm{~g})$ on (a) $\mathrm{q}_{e}$ and (b) $K_{d}$ for a certain concentration of the studied organic compounds
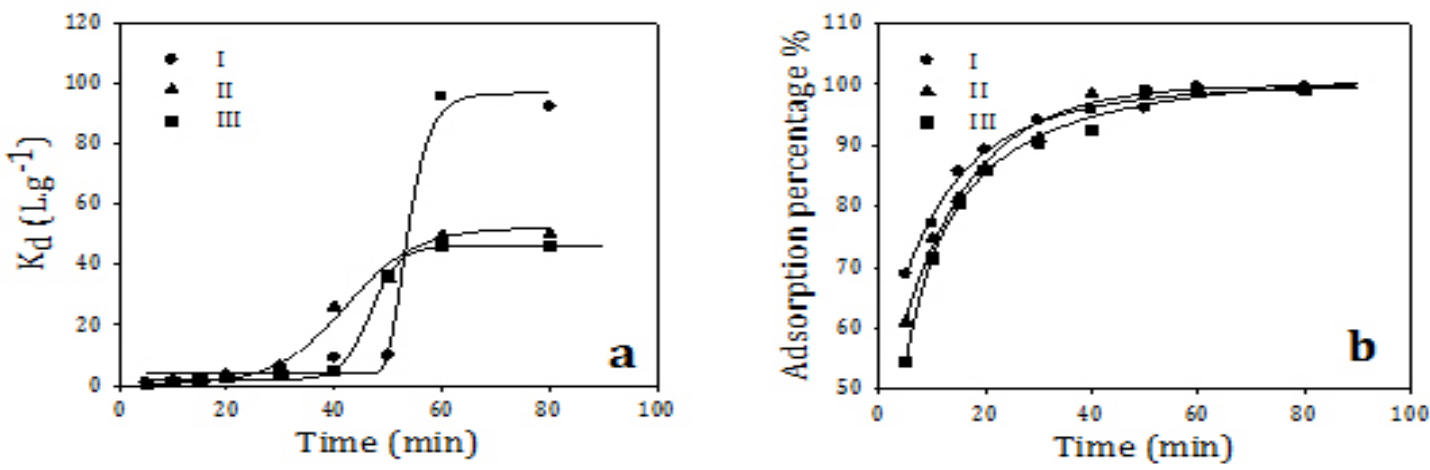

Fig. 3. Effect of the contact time (5-80 $\mathrm{min})$ for a certain concentration of the studied organic compounds on (a) $\mathrm{K}_{\mathrm{d}}$ and (b) Ads\% using Amberlite IR120 $\mathrm{H}^{+}$resin 
in the limited active sites on the resin surface. The adsorption is illustrated to a fast process where approximately $80 \%$ of the adsorption efficiency took place at the beginning of 10 minutes.

\section{Effect of the adsorbate initial concentration}

The effect of the initial concentrations of the organic compounds solutions, in the range of $1 \times 10^{-4}$ to $1.5 \times 10^{-3} \mathrm{M}$ at $30^{\circ} \mathrm{C}$ for $60 \mathrm{~min}$., for their adsorption on Amberlite IR-120 $\mathrm{H}^{+}$resin was described at Fig. 4. The Figure shows a gradual increase of the adsorption efficiency with increasing the adsorbate amount as a result of increasing the adsorbate cations around the active sites of the resin ${ }^{20}$. Consequently, the removal efficiency increased with increasing the adsorbate amount (Fig. 4-a). For certain, at low initial adsorbate concentrations, the ratio of an initial amount of organic cations to active sites of the resin was low. Hence, the removal efficiency of the cations was higher. On the other hand, at higher concentrations, the ratio of the cations and active sites was high. So that, the excess of the cations remained in the solution leading to a decline of the removal efficiency ${ }^{21}$. By all means, at low concentration of adsorbate, the number of organic cations was insufficient for covering the adsorbent surface and forming a layer in contrast to the high concentration of adsorbate with an adequate amount of cations that formed a single layer on the resin surface ${ }^{22}$.

\section{Effect of ionic strength}

The effect of ionic strength on the adsorption of organic cations on $0.25 \mathrm{~g}$ of Amberlite-IR $120 \mathrm{H}^{+}$ resin from aqueous solution was examined by using

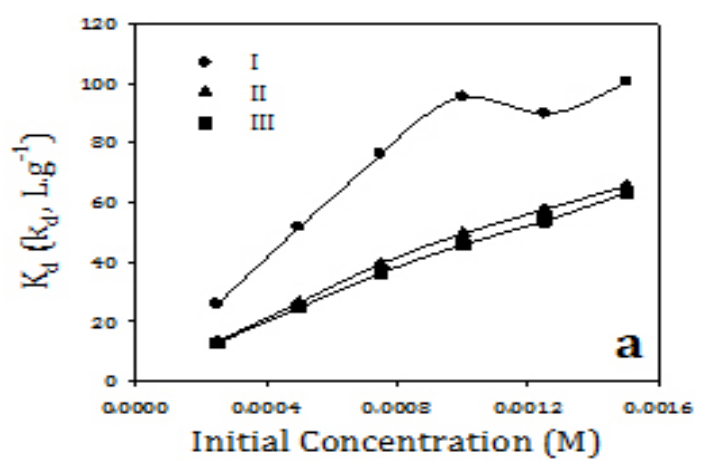

a variety of $\mathrm{NaCl}$ concentrations in the range from 0.05 to $1.0 \mathrm{M}$ at $30{ }^{\circ} \mathrm{C}$ for 60 minutes. The experimental results (Fig. 5) exhibit that, the adsorption decreased as $\mathrm{NaCl}$ concentrations increased. A possible implication is that there was a competition between $\mathrm{Na}^{+}$and organic cations to be adsorbed on the resin surface. For example, at lower $\mathrm{NaCl}$ concentrations, the effect of $\mathrm{Na}^{+}$cation was slight due to more functional groups were available for organic cations and $\mathrm{Na}^{+}$uptake. However, at higher $\mathrm{NaCl}$ concentrations, the competition between $\mathrm{Na}^{+}$and organic cations for the available sites became more significant leading to a low organic cations removal. That might be attributed to the greater selectivity of anionic sulfate groups of the resin for $\mathrm{Na}^{+}$cations than that for organic cations ${ }^{23}$ since $\mathrm{Na}^{+}$ions are smaller in size in comparison to organic cations and hence the mobility of $\mathrm{Na}^{+}$ is higher than organic cations ${ }^{24}$. Similar results represented by Wang ${ }^{25}$. For more explanation, the electrostatic interaction plays an essential role in the ion exchange technique. $\mathrm{Na}^{+}$cations coordinated with $\mathrm{R}-\mathrm{SO}_{3}$ anions that hindered the electrostatic attraction between the organic cations and the anion parts of the resin. Furthermore, with increasing the ionic strength, the electrical double layer thickness surrounding the molecules decreased ${ }^{26}$ leading to reduce the electrostatic force between adsorbent surface and adsorbate.

\section{Effect of temperature}

The effect of the solution temperature on the adsorption of organic cations on Amberlite-IR $120 \mathrm{H}^{+}$ resin from aqueous solution was studied by varying the temperatures $\left(30,50\right.$ and $\left.70^{\circ} \mathrm{C}\right)$ at the constant initial concentration $\left(1 \times 10^{-3} \mathrm{M}\right)$ and contact time

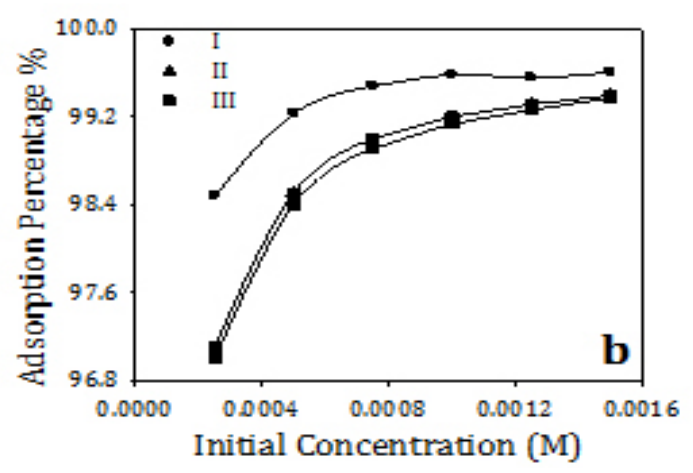

Fig. 4. Effect of the initial concentrations of the studied organic compounds $\left(2.5 \times 10^{-4}\right.$ to $1.5 \times 10^{-3} \mathrm{M}$ )) on (a) $\mathrm{K}_{\mathrm{d}}$ and (b) Ads\% using Amberlite IR-120 $\mathrm{H}^{+}$resin 
(60 minutes). The experimental results proved that there was a slight decrease in the adsorption with increasing the temperature (Fig. 6). The decrease in the adsorption indicates to an exothermic adsorption process which is favorable at lower temperatures. Therefore, the physical adsorption is predominated in this case. The reason behind the decrease in the adsorption of the organic compounds is the weakness of the adsorptive forces between the

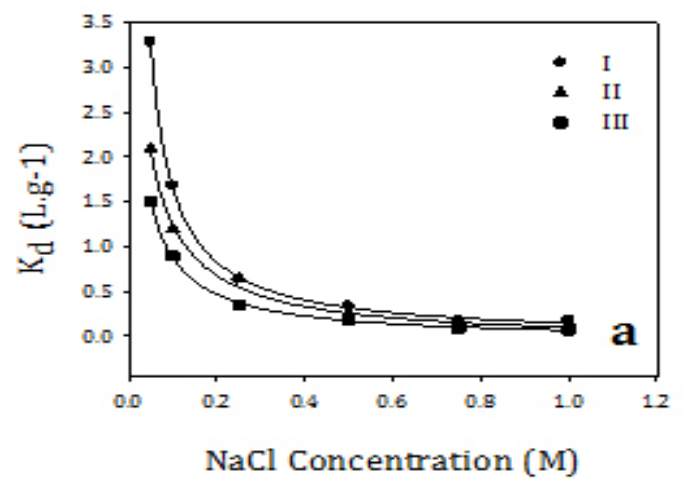

adsorbent surface and the organic cations and also between the adjacent ions of the adsorbed cations and the adsorbent surface. At higher temperatures, some active sites on the adsorbent surface destructed due to bond rupture and hence the surface might be reformatted ${ }^{27}$. Generally speaking, the temperature has a small effect on the adsorption which decreased as temperature increased.

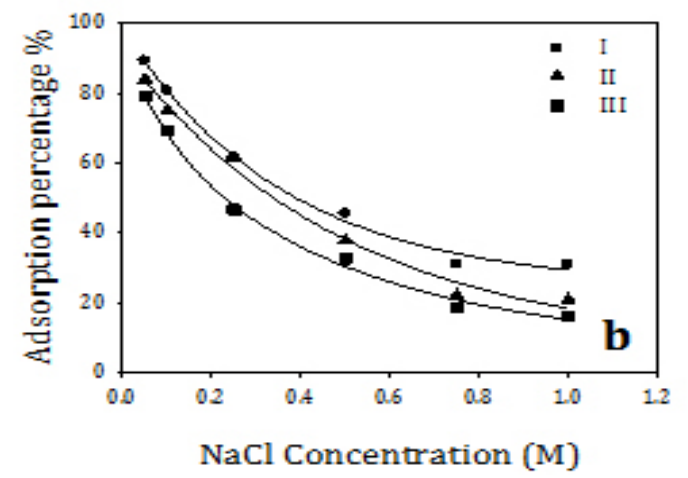

Fig. 5. Effect of $\mathrm{NaCl}(0.05$ to $1.0 \mathrm{M})$ for a certain concentration of the studied organic compounds on (a) $\mathrm{K}_{d}$ and (b) Ads\% using Amberlite IR $120 \mathrm{H}^{+}$resin
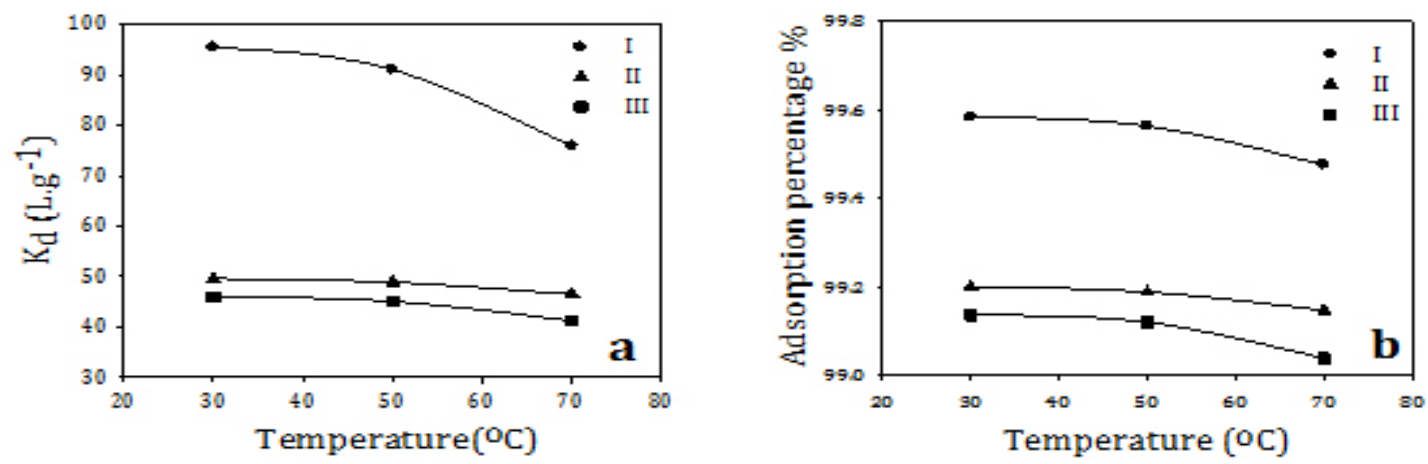

Fig. 6. Effect of the solution temperature $\left(30,50\right.$ and $\left.70{ }^{\circ} \mathrm{C}\right)$ for a certain concentration of the studied organic compounds on (a) $\mathrm{K}_{\mathrm{d}}$ and (b) Ads\% using Amberlit IR $120 \mathrm{H}^{+}$resin.

Thermodynamic evaluation for the adsorption of the studied organic compounds on Amberlite IR $120 \mathrm{H}^{+}$resin

Thermodynamic parameters such as change in free energy $\left(\Delta \mathrm{G}^{\circ}\right)$ enthalpy change $\left(\Delta \mathrm{H}^{\circ}\right)$ and entropy change $\left(\Delta S^{\circ}\right)$ for the adsorption of the studied organic compounds from aqueous solution on Amberlite IR $120 \mathrm{H}^{+}$resin were investigated at 30,50 and $70^{\circ} \mathrm{C}$. The following equation determines the Gibbs free energy of adsorption $\left(\Delta \mathrm{G}^{\circ}\right)$ based on the $\mathrm{K}_{\mathrm{d}}$ value.
$\Delta G^{\circ}=-R T . \ln K_{d}$

$\Delta \mathrm{S}^{\circ}$ and $\Delta \mathrm{H}^{\circ}$ values calculate from the slopes and intercepts of the straight lines of Fig. 7 respectively based on Van't Hoff equation that given below ${ }^{28}$.

In $\mathrm{Kd}=\Delta \mathrm{S}^{\circ} / \mathrm{R}-\Delta \mathrm{H}^{\circ} / \mathrm{RT}$

The thermodynamic parameters represented in Table 2. The negative values of $\Delta \mathrm{G}^{\circ}$ 
represent the feasibility and spontaneous nature of the adsorption process. As it is shown in the Table, $\Delta G^{\circ}$ values did not indicate a significant change with increasing the temperature. Generally speaking, the adsorption was physisorption since $\Delta \mathrm{G}^{\circ}$ were less than $20 \mathrm{Kj} / \mathrm{mol}^{-1}$. However, the positive values of $\Delta \mathrm{S}^{\circ}$ suggest high affinity of the adsorbent to the adsorbate and prove that the randomness increased at the solid-liquid interface during adsorption process ${ }^{1,29}$. This positive entropy as a result of the release of water molecules structures that were surrounded the organic cations upon their association. The

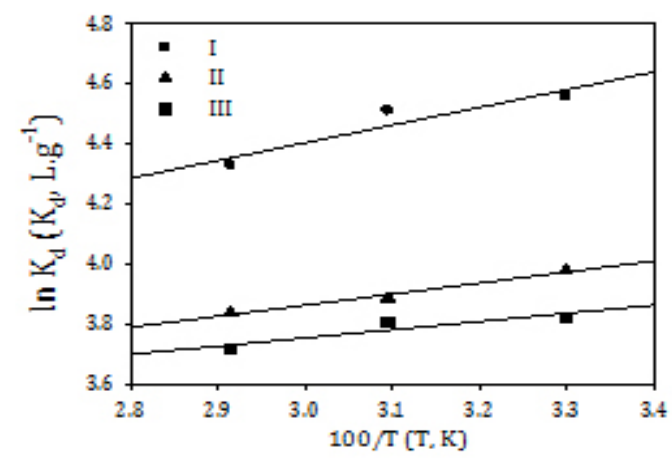

Fig. 7. Van't Hoff plot of the effect of temperature $\left(30,50\right.$ and $\left.70^{\circ} \mathrm{C}\right)$ on the adsorption of the studied organic compounds on Amberlite-IR $120 \mathrm{H}^{+}$ reason behind the small positive values of entropy is that when the organic cations were adsorbed on the adsorbent surface, they became less free to move around than that in the solution ${ }^{30}$. The entropy increased slightly with increasing the chain length. To an illustration, the aggregations of the organic molecules became tighter with increasing the alkyl chain length leading to more release of water molecules and higher entropy ${ }^{31}$. In addition to that, $\Delta \mathrm{H}^{\circ}$ are negatively illustrating that the adsorption was exothermic processes. The negative value of $\Delta \mathrm{H}^{\circ}$ might be contributed to the direct ionic bond formation between the organic cations and the ionic sites of the adsorbent surface. Also, the reaction did not involve activation energy ${ }^{30}$. One possible reason for the increase of the enthalpy negativity with decreasing the chain length is that as the electrostatic interactions increased, stronger bonds formed resulting in more energy released and hence more exothermic, large negative value and greater adsorption capacity.

Overall, the adsorption is physical since the $\Delta \mathrm{H}^{\circ}$ values are less than $40 \mathrm{Kj} \mathrm{mol}^{-1}$. In general, the thermodynamic data proved that the adsorption decreased as the alkyl chain length increased as follows.

$$
\text { I }>\text { II }>\text { III }
$$

Table 1: Names, Abbreviations, molecular weights and chemical structures of the studied organic compounds

\begin{tabular}{cccc}
\hline Organic & Molecular & Chemical structure & Name \\
compound & weight $(\mathrm{g})$ & &
\end{tabular}

353.1982<smiles>COc1ccc(/C=C/c2cc[n+](C)cc2)cc1</smiles>

1-methyl-4[4'-(OMe) styryl] pyridinium lodide

II

367.2247

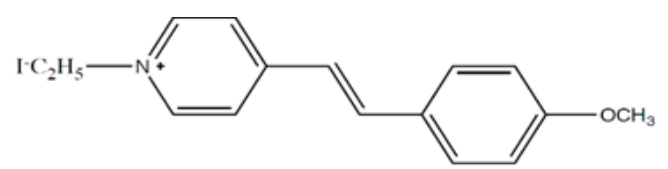

1-ethyl-4[4'-(OMe) styryl] pyridinium lodide

III

381.2513

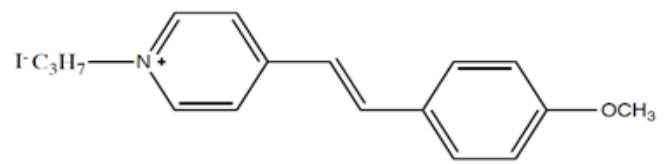

1-propyl-4[4'-(OMe) styryl] pyridinium lodide 
Table 2: Thermodynamic parameters of the adsorption of the studied organic compounds on Amberlite-IR $120 \mathrm{H}^{+}$resin at $\left(30,50\right.$ and $\left.70^{\circ} \mathrm{C}\right)$

\begin{tabular}{cccccc}
\hline & \multicolumn{5}{c}{$\Delta \mathrm{G}^{\circ}\left(\mathrm{Kjmol}^{-1}\right)$} \\
$\begin{array}{l}\text { Organic } \\
\text { compound }\end{array}$ & $\Delta \mathrm{H}^{\circ}\left(\mathrm{Kjmol}^{-1}\right)$ & $\Delta \mathrm{S}^{\circ}\left(\mathrm{Jmol}^{\left.-1 \mathrm{~K}^{-1}\right)}\right.$ & $30^{\circ} \mathrm{C}$ & $50^{\circ} \mathrm{C}$ & $70^{\circ} \mathrm{C}$ \\
\hline I & & & & & \\
II & -4.896 & 21.9 & -11.488 & -12.120 & -12.355 \\
III & -3.059 & 23.0 & -10.031 & -10.613 & -10.953 \\
\hline
\end{tabular}

Adsorption isotherm models for the studied organic compounds on Amberlite IR-120 $\mathrm{H}^{+}$resin

Langmuir Freundlich, Temkin and D.R isotherm models were applied to the adsorption of the studied organic compounds, at a different initial concentration $\left(2.5 \times 10^{-4}\right.$ to $\left.1.5 \times 10^{-3} \mathrm{M}\right)$, from aqueous solution on Amberlite-IR $120 \mathrm{H}^{+}$resin at $30{ }^{\circ} \mathrm{C}$. However, modeling of Langmuir for the adsorption system was unacceptable since it gave negative values for $\mathrm{q}_{\mathrm{m}}$.

\section{Freundlich isotherm model}

Figure 8 illustrates that log qe against log $\mathrm{C}_{\mathrm{e}}$ plots gave bilinear segments model based on the

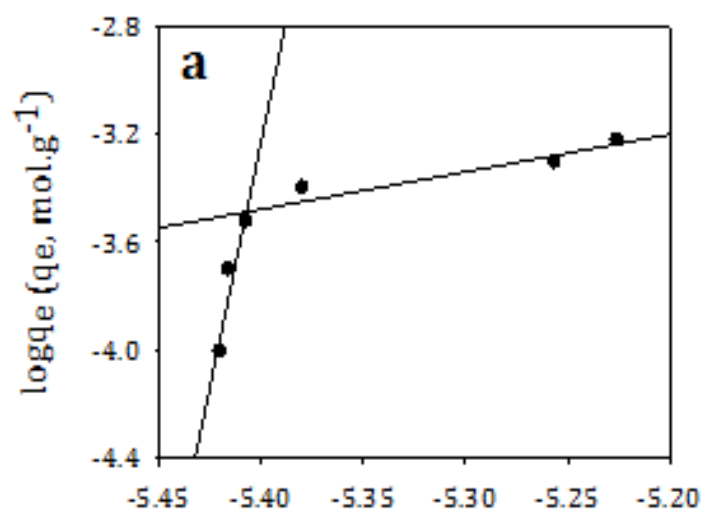

adsorbate initial concentrations. As it is shown at Table 3, the first part is following the experimental data since it gave the same order for the adsorption capacities of the studied organic compounds as following: |> II> III. However, an opposite order was obtained at the second part. The interpretation of that will be discussed in more detail later. Overall, the mean value of the adsorption capacity fits the experimental data and follows the same order, I> II>III. According to Table $3, n$ values for the studied organic compounds are less than one which refers to that the surface of the adsorbent is heterogeneous and is considered as S-type isotherm ${ }^{32,33}$.

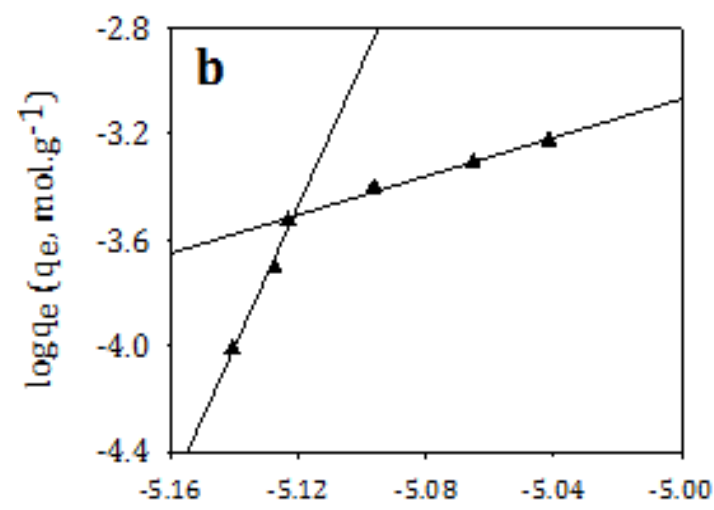

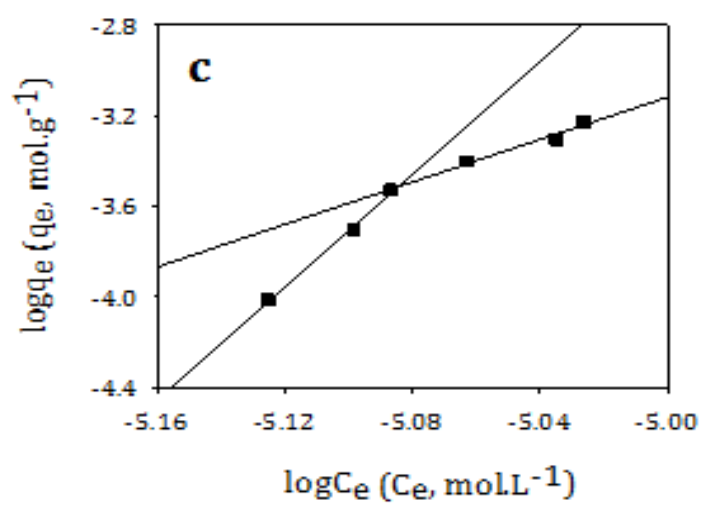

Fig. 8. Freundlich isotherm model for the adsorption of (a; I), (b; II) and (c; III) on Amberlite-IR $120 \mathrm{H}^{+}$resin 
Table 3: Freundlich isotherm parameters for the adsorption of the studied organic compounds on Amberlite-IR $120 \mathrm{H}^{+}$resin

\begin{tabular}{|c|c|c|c|c|c|c|c|c|c|}
\hline \multirow[b]{2}{*}{$\begin{array}{l}\text { Organic } \\
\text { compound }\end{array}$} & \multirow[b]{2}{*}{$\mathrm{n}_{1}$} & \multirow[b]{2}{*}{$\log K_{F 1}$} & \multirow[b]{2}{*}{$r_{1}^{2}$} & \multirow[b]{2}{*}{$\mathrm{n}_{2}$} & \multirow[b]{2}{*}{$\log K_{F 2}$} & \multirow[b]{2}{*}{$\mathrm{r}_{2}^{2}$} & \multicolumn{3}{|c|}{ Mean value } \\
\hline & & & & & & & $\mathrm{n}$ & $\begin{array}{c}\log K_{F} \\
\left(k_{F}, \mathrm{~mol} \mathrm{~g}^{-1}\right)\end{array}$ & $r^{2}$ \\
\hline I & 0.027 & 192.183 & 0.89 & 0.723 & 3.995 & 0.91 & 0.375 & 98.089 & 0.9 \\
\hline II & 0.037 & 133.65 & 0.98 & 0.381 & 9.997 & 0.87 & 0.209 & 71.824 & 0.93 \\
\hline III & 0.081 & 59.595 & 0.99 & 0.214 & 20.262 & 0.99 & 0.116 & 39.929 & 0.99 \\
\hline
\end{tabular}

\section{Temkin Isotherm model}

Temkin model was applied by plotting $q_{e}$ versus $\ln \mathrm{C}_{\mathrm{e}}$ as shown in Fig 9 . As it is seen, Temkin model for I and II represents two straight lines for the adsorption process indicating two different adsorption energies ${ }^{34}$ while Temkin model for III appears in one straight line. The reason behind that also will be interpreted later. According to Table 4, $B$ mean values decreased significantly with increasing the chain length of the organic compounds indicating a weakness of the interaction as the chain length increased. Both lines have the same trend in which

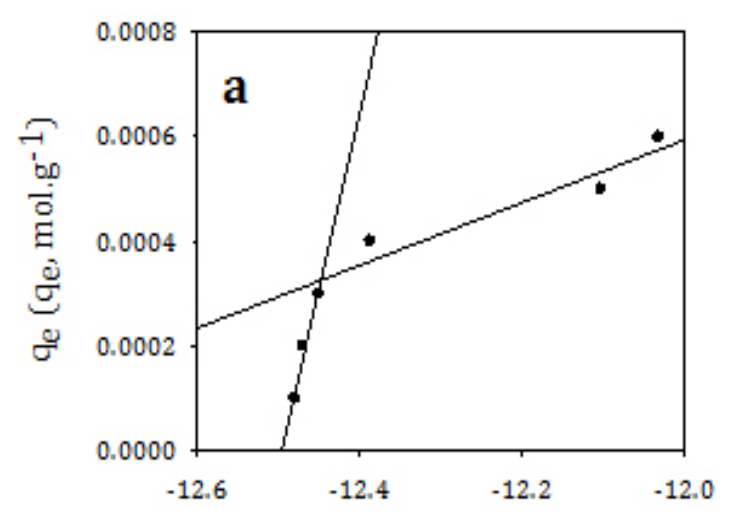

the adsorption capacity decreased with increasing the chain length of the studied organic compounds. According to $\mathrm{K}_{\mathrm{T}}$ mean values, the organic compound I relieves the highest binding energy and thus highest adsorption capacity than others. That is to say, the adsorption capacity follows the order of I >II >III confirming the experimental data. Also, the correlation coefficients of Temkin model were maximum for all the studied compounds. Hence, the adsorption processes followed Temkin model satisfactorily.

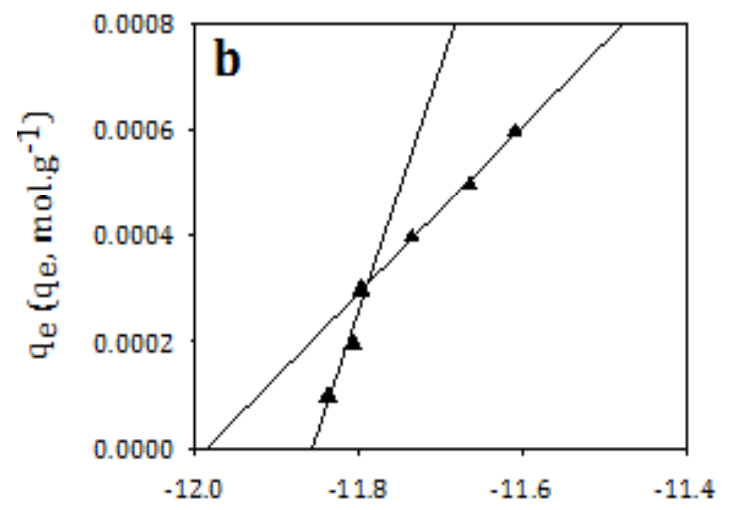

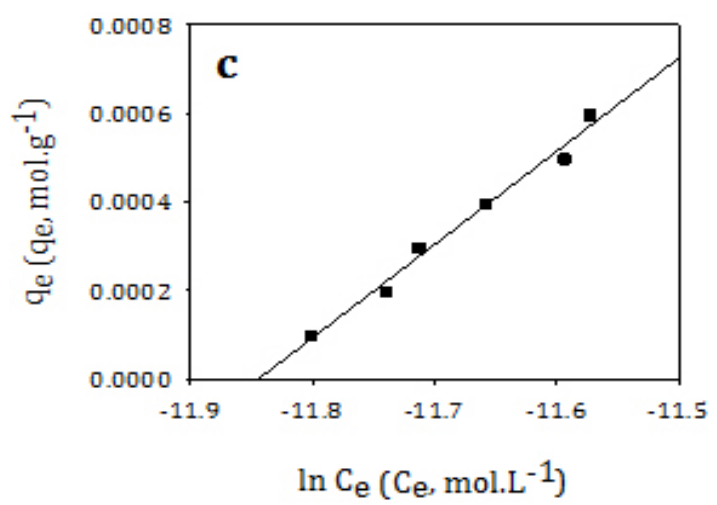

Fig. 9. Temkin isotherm model for adsorption of (a; I), (b; II) and (c; III) on Amberlit- IR $120 \mathrm{H}^{+}$resin. 
Table 4: Temkin isotherm parameters for the adsorption of the studied organic compounds on Amberlite-IR $120 \mathrm{H}^{+}$resin

\begin{tabular}{|c|c|c|c|c|c|c|c|c|c|}
\hline \multirow[b]{2}{*}{$\begin{array}{l}\text { Organic } \\
\text { compound }\end{array}$} & \multirow[b]{2}{*}{$\mathrm{B}_{1}$} & \multirow[b]{2}{*}{$\mathrm{k}_{\mathrm{T} 1}$} & \multirow[b]{2}{*}{$\mathrm{r}^{2}{ }_{1}$} & \multirow[b]{2}{*}{$\mathrm{B}_{2}$} & \multirow[b]{2}{*}{$\mathrm{k}_{\mathrm{T} 2}$} & \multirow[b]{2}{*}{$\mathrm{r}_{2}^{2}$} & \multicolumn{3}{|c|}{ Mean value } \\
\hline & & & & & & & $\begin{array}{c}\mathrm{B} \\
\left(\mathrm{B}, \mathrm{Kj} \cdot \mathrm{mol}^{-1}\right)\end{array}$ & $\mathrm{K}_{\mathrm{T}}, \mathrm{mol}_{\mathrm{T}}$ & 1) $r^{2}$ \\
\hline I & 6.719 & 1.0124 & 0.97 & 6.006 & 3.668 & 0.93 & 6.363 & 2.34 & 0.95 \\
\hline II & 4.582 & 1.0118 & 0.92 & 1.567 & 1.0121 & 0.99 & 3.075 & 1.012 & 0.96 \\
\hline III & 2.104 & 1.011 & 0.99 & - & - & - & - & - & - \\
\hline
\end{tabular}

\section{D.R isotherm model}

D.R isotherm model was applied as exhibited at Fig. 10. Plotting $\ln C_{e}$ versus $\varepsilon^{2}$, it was obtained two linear segments. As it is shown in Table 5, the maximum adsorption capacity has the order of I> II > III for the first line while the order is reversed for the second line. In general, the mean maximum adsorption capacity order corresponded well to the experimental data. It is clear that $E_{2}>E_{1}$ for II and III and that means the required energy to remove one molecule from the bulk of the solution to the top of the adsorbent surface increased with increasing the adsorbate initial concentration. In addition to that the shortest alkyl chain length (I) has the lowest value of $E$ and that might be contributed to the weakness of the hydrophobic effect for the studied compound I. The data illustrate that the $\mathrm{E}$ values were less than 8 indicating that physical adsorption played a crucial part in the adsorption process $^{35}$. Since the adsorption process is physical, it should be exothermic, and that is in agreement with the enthalpy values as represented at Table (2).
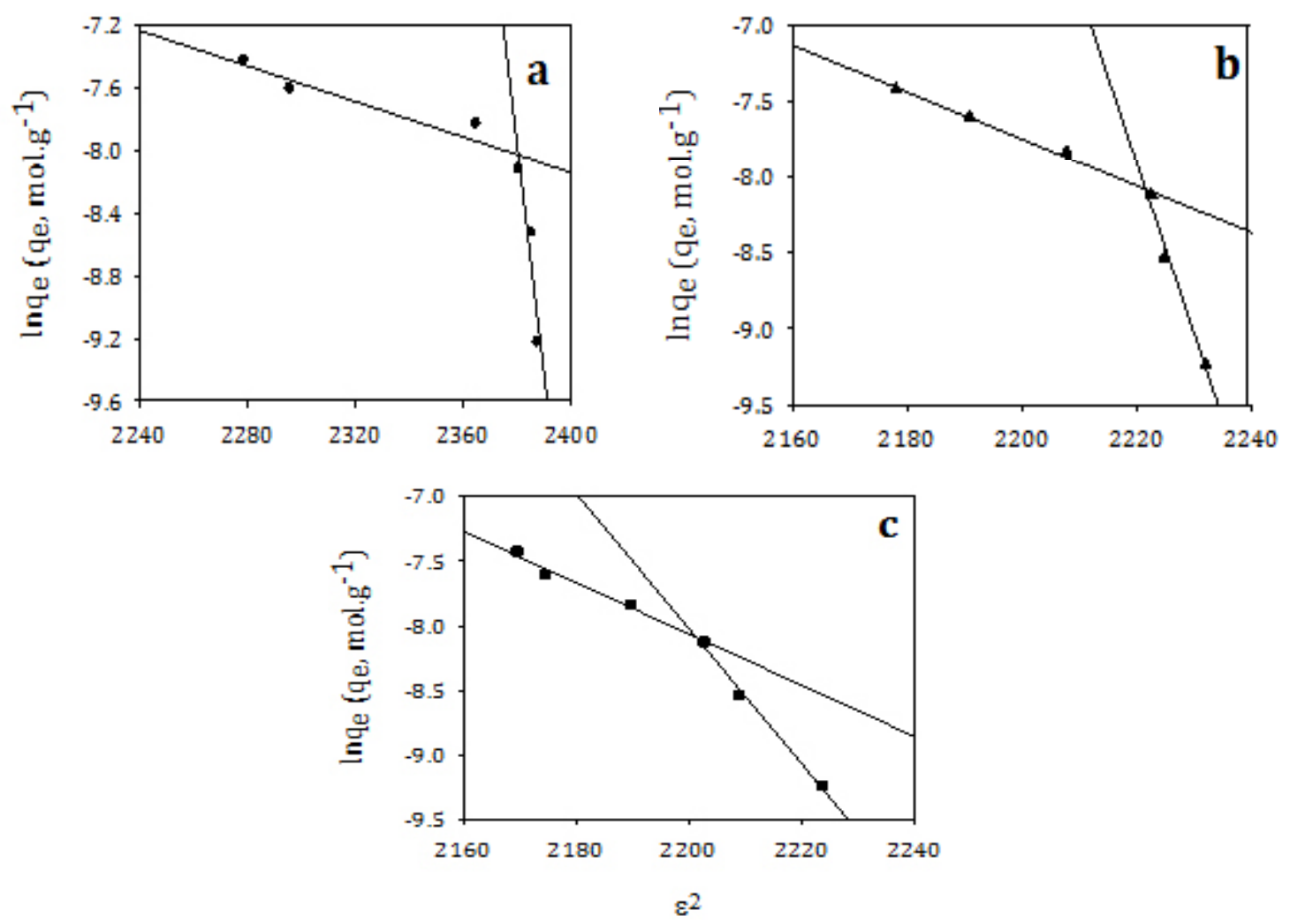

Fig. 10. Dubinin-Radushkevich isotherm model for adsorption of (a; I), (b; II) and (c; III) on Amberlite- IR $120 \mathrm{H}^{+}$resin 
Table 5: Dubinin-Radushkevich isotherm parameters for the adsorption of the studied organic compounds on Amberlite-IR $120 \mathrm{H}^{+}$resin

\begin{tabular}{|c|c|c|c|c|c|c|c|c|c|}
\hline \multirow[b]{2}{*}{$\begin{array}{l}\text { Organic } \\
\text { compound }\end{array}$} & \multirow[b]{2}{*}{$\mathrm{InK}_{\mathrm{s} 1}$} & \multirow[b]{2}{*}{$E_{1}$} & \multirow[b]{2}{*}{$\mathrm{r}^{2}{ }_{1}$} & \multirow[b]{2}{*}{$\operatorname{lnK}_{\mathrm{s} 2}$} & \multirow[b]{2}{*}{$\mathrm{E}_{2}$} & \multirow[b]{2}{*}{$\mathrm{r}_{2}^{2}$} & \multicolumn{3}{|c|}{ Mean value } \\
\hline & & & & & & & $\left(\mathrm{K}_{\mathrm{s}}, \mathrm{InK}_{\mathrm{s}} \mathrm{mol}^{-1}\right)$ & $\begin{array}{c}\mathrm{E} \\
\left(\mathrm{E}, \mathrm{Kj} \cdot \mathrm{mol}^{-1}\right)\end{array}$ & $r^{2}$ \\
\hline I & 341.999 & 1.844 & 0.89 & 5.511 & 0.296 & 0.91 & 173.755 & 1.07 & 0.9 \\
\hline II & 241.98 & 6.652 & 0.98 & 16.706 & 6.742 & 0.87 & 129.343 & 6.697 & 0.93 \\
\hline III & 107.108 & 3.1 & 0.99 & 35.584 & 5.025 & 0.98 & 71.346 & 4.063 & 0.99 \\
\hline
\end{tabular}

Interpretation of the adsorption characteristics for the studied organic compounds on Amberlite-IR $120 \mathrm{H}^{+}$resin on the light of chain length effect

The evidences gathered from the isotherm models for the adsorption of some $\mathrm{N}$-alkyl pyridinium salts from aqueous solution on Amberlite IR $120 \mathrm{H}^{+}$resin show that the models had two parts according to the initial adsorbate concentrations. At low concentrations, the organic cations were free to move around the adsorption interface where the active adsorption sites were more available. Hence, the adsorption was dominated by ion exchange reaction. In this case, van der walls attractive forces are considered as the driving force for the ion exchange in addition to the electrostatic forces between the organic cations and the oppositely charged of the adsorbent surface ${ }^{36}$. Furthermore, the alkyl chain tails of the organic compounds adsorbed parallel to the surface at the interface. Besides, this orientation of the alkyl chains might be contributed to inhibit the interactions between the chains of the organic compounds and reduce the hydrophobic interactions at this region ${ }^{37,38}$. From the experimental data it can be observed that, the adsorptive amounts of the studied organic cations onto Amberlite IR $120 \mathrm{H}^{+}$resin decreased with increasing the alkyl chain length at low adsorbate concentrations due to the diminution of the electrostatic attractive forces between the studied organic cations and the adsorbent surface. That occurred as a result of the steric hindrance which associated with the binding of a large molecule on the active sites of the resin surface blocking the access to unoccupied active sites $^{39}$. However, at high equilibrium concentrations, the active adsorption sites became less available since the majority of the sites were occupied by the organic cations in order to neutralize the surface charge; so that, the electrostatic interaction became less. For this reason any further adsorption in this stage was a result of the hydrophobic interaction that was controlled by van der Waals forces. Certainly, as the adsorbate amount increased in solutions, the adsorbent surface became hydrophobic due to the orientation of the alkyl chains perpendicular towards the bulk solution ${ }^{37,38}$. The increase of hydrophobicity on the surface made the system unstable due to increase the system energy. In order to obtain a stable system, hydrophobic interactions took place between the tails of the organic compounds at the adsorbent surface, between the tails that existed in solution, and also between the tails and the adsorbent surface when adsorption carried out on hydrophobic sites. Further increased in the concentration generated aggregations of the organic cations on the adsorbent surface through van der walls forces or hydrophobic binding. Consequently, the organic cations appeared to adsorb as multilayers ${ }^{40}$. Based on the Freundlich and D.R isotherm models increasing alkyl chain length increased the maximum amount adsorbed at saturation fundamentally due to increase the hydrophobic interaction. For more explanation, as the chains length increased, the hydrophobic interaction between alkyl groups became stronger and thus the organic compounds tend to gather away from aqueous medium to adsorb on the surface of the adsorbent ${ }^{36}$. That because the organic cations with increasing alkyl chain length have a much greater driving force for the aggregation. In the regard to Temkin isotherm model that represents two straight lines for the adsorption process of I and II indicating two different adsorption energies. The first part (low initial concentration) involves high interaction energy in which the high electrostatic attractions were dominated. However, the second part (high initial concentration) includes lower interaction energy in which the weak van-der Waals forces were dominated. As a result, the adsorption energy broke down into two parts ${ }^{41}$. According to III compound, the steric hindrance weaken the electrostatic interaction in the first part in addition to the weak van-der Waals forces at the second one; so that the adsorption energy for III 
appeared in one line since there was no difference in the adsorption energy between the two parts. In short, the alkyl chain length affect the adsorption isotherm leading to the appearance of bilinear adsorption models.

\section{Scanning Electron Microscope (SEM) analysis of the resin}

SEM images of Amberlite IR- $120 \mathrm{H}^{+}$resin before and after its adsorption of the studied organic compounds, $\left(1 \times 10^{-3}\right)$ from aqueous solution at

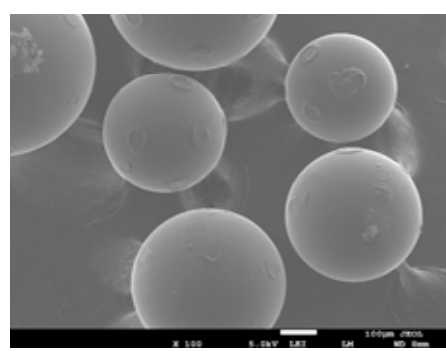

(a)

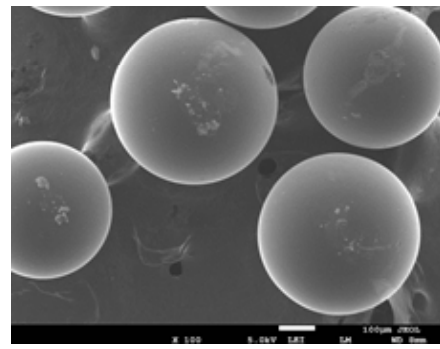

(b)

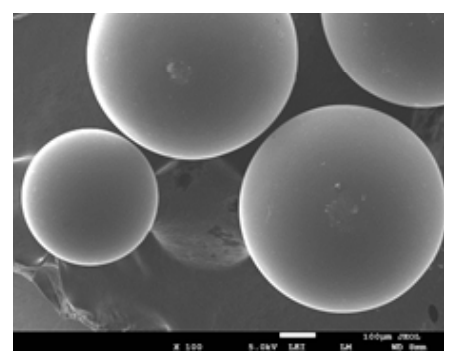

(II)

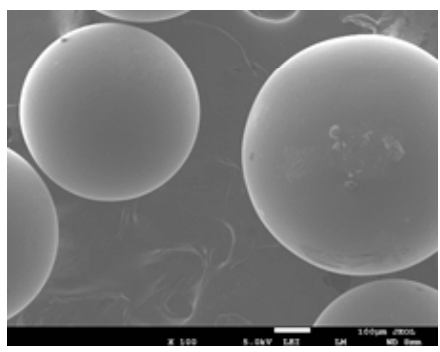

(III)

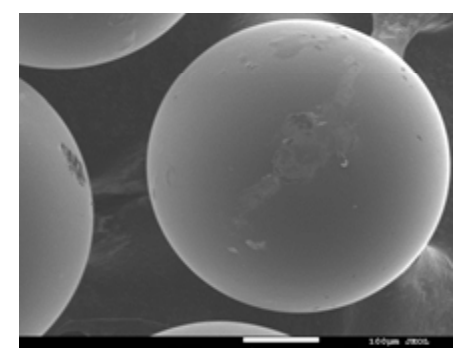

(I)
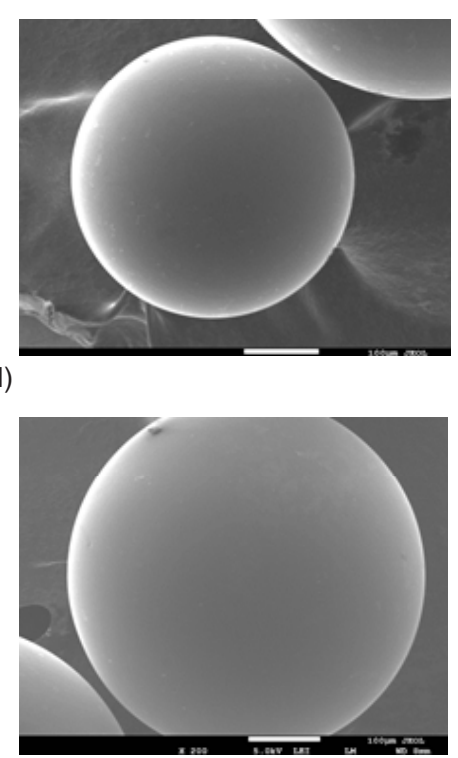

$30{ }^{\circ} \mathrm{C}$ for $60 \mathrm{~min}$. are shown in Fig. 11. As could be observed, there is an obvious change of the resin surface morphology proven the adsorption of the studied compounds onto the adsorbent. It is clearly seen that the resin surface before contact was rough; however, the surface became smoother with increasing the chain length. The possible implication, for this case, is that physical sorption took more place with longer alkyl chain forming multilayers on the surface and making the surface smoother while it took less place with shorter alkyl chain where the ion exchange was dominated.

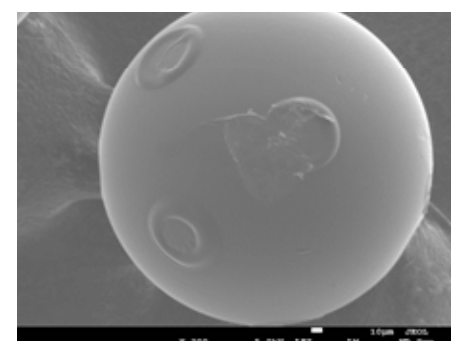

Fig. 11. SEM of Amberlite IR $120 \mathrm{H}+$ resin(a) before and (b) after adsorption the studied organic compounds 


\section{CONCLUSION}

The study proved the high capability of Amberlite-IR $120 \mathrm{H}^{+}$resin to remove some of the $\mathrm{N}$-alkyl pyridinium salts from the aqueous medium under certain conditions. The results represent that the adsorption increased significantly with increasing the resin dosage, contact time, adsorbate concentration. However, adding $\mathrm{NaCl}$ to the organic solution or increasing the temperature of the solution decreased the adsorption. The thermodynamic data show that the adsorption is spontaneous, disordered and exothermic. Temkin model described the adsorption systems appropriately. The isotherm models break down the adsorption into two regions according to the adsorbate initial concentrations. The experimental data in overall indicate that the adsorption efficiency decreased with increasing the alkyl chain length at the low concentration where the adsorption was dominated by ion exchange reaction.

\section{ACKNOWLEDGMENT}

This study was supported by the Department of Physical Chemistry, Science Faculty, King Abdul Aziz University, Jeddha.

\section{REFERENCES}

1. Poulopoulos, S. G.; Inglezakis, V. J. Ads. Ion. Exch. Cat.: Des. Oper. Env. App. Elsevier. 2006, 602.

2. Nasef, M. M.; Ujang, Z. Ion. Exch. Tech., 2012, 1-39.

3. The Dow Chemical Company, $2018 \mathrm{https}: / /$ www.dow.com/webapps/include/GetDoc. aspx?filepath=liquidseps/pdfs/noreg/17703048.pdf.

4. Helfferich, F. Ion. Exch., 1995, 624.

5. Langmuir I. J. Am. Chem. Soc., 1918, 40, 1361-1403.

6. Freundlich, H.; Hatfield, H. S. Coll. Capl. Chem., 1926, 916, 397-414.

7. Temkin, M. I. Acta. phys., 1940, 12, 327-356.

8. Dubinin, M. M.; Radushkevich, L. V. Dokl. Akad. Nauk., 1947, 55, 331-334.

9. Özcan, A.; Öncü; E. M.; Özcan, A. S. Physico. Eng. Asp., 2006, 277, 90-97.

10. Noor, E. A.; Al-Solmi, F. M. J. Chem., 2011, 8(1), 171-S188.

11. Al-Ahmari J.M. Ph.D. Thesis at K. A. U., 2011, 250, 75-76.

12. Florkin, M.; Stotz, E. H. Bioenergetics. Elsevier., 2014, 22.

13. Vogel, A. I. Quan. Inorg. Ana., 3rd ed. 1961, 1216.

14. Miller, F. P.; Vandome, A. F.; McBrewster, J. Adv encr standard., 2009, 110.

15. Pons, M. P.; Fuste, M. C. Appl. Micro. Biotech., 1993, 39, 661-665.

16. Rengaraj, S.; Joo, C. K.; Kim, Y.; Yi, J. J. Haz. Mat., 2003, 102, 257-275.
17. Yu, Z.; Qi, T.; Qu, J.; Wang, L.; Chu, J. J. Haz. Mat., 2009, 167, 406-412.

18. Mandal, S.; Sahu, M. K.; Patel, R. K. Wat. Reso. Ind., 2013, 4, 51-67.

19. Said, A.; Hakim, M. S.; Rohyami, Y. Int'I Confer. Chem. Bio. Env. Sci., 2014, 11-13.

20. Ghorbani, F.; Younesi, H.; Ghasempouri, S. M.; Zinatizadeh, A. A.; Amini, M.; Daneshi, A. Chem. Eng. J., 2008, 145, 267-275

21. Radnia, H.; Ghoreyshi, A. A.; Younesi, H.; Najafpour, G. D. Des. Wat. Treat., 2012, 50, 348-359.

22. Tang, Y.; Wang, X.; Zhu, L. Poly. Bull., 2013, 70, 905-918.

23. Sharma, S.; Agarwal, G. P. J. Coll. Interf. Sci., 2001, 243, 61-72.

24. Hu, Y.; Guo, T.; Ye, X.; Li, Q.; Guo, M.; Liu, H.; Wu, Z. Chem. Eng. J., 2013, 228, 392-397.

25. Wang, S.; Dong, Y.; He, M.; Chen, L.; Yu, X. App. Cla. Sci., 2009, 43, 164-171.

26. Debye, P.; Hückel, E. Phys. Zeit., 1923, 24, 185-206.

27. Akazdam, S.; Chafi, M.;Yassine, W.; Gourich, B. J. Mat. Env. Sci., 2017, 8, 2993-3012.

28. Abou-Mesalam, M. M. Coll. Surf., 2003, 225, 85-94.

29. Kumar, P. S.; Gayathri, R. J. Eng. Sci. Technol., 2009, 4, 381-399.

30. Somasundaran, P.; Fuerstenau, D. W. Transactions., 1973, 254.

31. Brandal, Ø. ; Hanneseth, A. M; Sjöblom, J. Coll. Poly. Sci., 2005, 284, 124-133. 
32. Varshney, R.; Bhadauria, S.; Gaur, M. S. 37. Gupta, V. K.; Mittal, A.; Krishnan, L.; Mittal, J. Water., 2011, 2, 142-151. J. Coll. Interf. Sci., 2006, 293, 16-26.

33. Giles, C.H.;MacEwan, T.H.;Nakhwa, S.N.;Smith, D. J. Chem. Soc. Resu., 1960, 3973-3993.

34. Maatar, W.; Alila, S.; Boufi, S. Ind. Crop. Prod. 2013, 49, 33-42.

35. Runping, H. A. N.; Pan, H. A. N.; Zhaohui, C. A. I.; Zhenhui, Z. H. A. O.; Mingsheng, T. A. N. G. J. Env. Sci., 2008, 20, 1035-1041.

38. Somasundaran, P.; Zhang, L. J. Pet. Sci. Eng., 2006, 52, 198-212.

39. Hassan, S.; Duclaux, L.; Lévêque, J. M.; Reinert, L.; Farooq, A.; Yasin, T. J. Env. Mana., 2014, 144, 108-117.

40. Ersoy, B.; Çelik, M. S. Cla. Cla. Min., 2003, 51, 172-180.

36. Paria, S.; Yuet, P. K. Ind. Eng. Chem. Res., 2006, 45, 712-718.

41. Piccin, J. S.; Dotto, G. L.; Pinto, L. A. A. Braz. J. Chem. Eng., 2011, 28, 295-304. 